\title{
HACIA UNA POLÍTICA INTEGRAL DEL HÁBITAT. APORTES PARA UN OBSERVATORIO DE POLÍTICA HABITACIONAL EN ARGENTINA
}

RED EPMA. CAFÉ DE LAS CIUDADES. COLECCIÓN HÁBITAT, 2016. 536 P.

ISBN: 978-987- 3627-01-9

Andrea Eliana Sarracina ${ }^{1}$

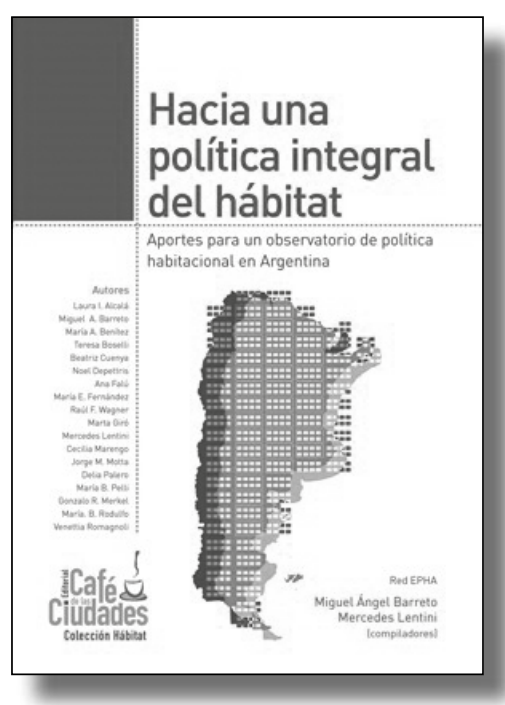

La obra titulada Hacia una política integral del hábitat. Aportes para un observatorio de politica habitacional en Argentina centra su estudio en el tema de la vivienda social y en las políticas habitacionales implementadas. Si bien el tema como problema social es analizado en numerosas publicaciones -pero en forma separada- por los autores, el libro reseñado tiene la particularidad de reunir gran parte de esas

1 Argentina. Profesora asociada Instituto de Geografía Aplicada y Departamento de Geografía de la Facultad de Filosofía, Humanidades y Artes, Universidad Nacional de San Juan. ORCID: https://orcid.org/0000-0002-6334-7170. Correo electrónico: asarraci@yahoo.com.ar.

investigaciones, con el fin caracterizar claramente el tema. Los destacados autores integran la Red de Estudios de la Política Habitacional Argentina [EPHA], con figura de observatorio, que tiene a su cargo la observación sistemática y la evaluación de la política pública de vivienda.

Los compiladores de la obra -Miguel Ángel Barreto (Universidad Nacional del Nordeste) y Mercedes 
Lentini (Universidad Nacional de Cuyo)- han logrado un trabajo ameno que puede ser consultado por estudiantes y profesionales que deseen conocer sobre un tema con plena vigencia en el país como son las políticas habitacionales y los distintos temas sociales relacionados; tanto en su evolución como en su implementación actual.

Los compiladores han organizado el libro en dos partes, la primera de ellas titulada "Perspectivas teóricas y metodológicas sobre la política habitacional", en la que se abordan temas de índole teórica y metodológica sobre la política de vivienda; y la segunda, denominada "Política habitacional Argentina a comienzos del siglo XXI", en la que se muestran ejemplos de casos en los que se han implementado diferentes programas habitacionales correspondientes a la política habitacional vigente.

Todo ello precedido por el prólogo de Víctor Pelli, quien, además de plantear el tema de la demanda de vivienda social como un problema, reconoce la necesidad e importancia de la conformación de la Red y del observatorio. Expresa el deseo de que la investigación y la publicación de las mismas continúen de forma sistemática.

La primera parte del libro comprende cinco trabajos de reconocidos investigadores de universidades y centros de investigación dedicados al tema de la vivienda, las políticas habitacionales, hábitat, etc.
En el primer trabajo, Raúl Fernández Wagner contextualiza, en primer lugar, el tema de la política de vivienda en el Estado de Bienestar y su evolución reciente en Europa; en segundo lugar, caracteriza claramente el sistema de vivienda pública en Argentina, cuyo análisis comprende siete etapas que van desde 1915 a la actualidad (posterior al año 2011), planteando la incógnita si se trata de neo-desarrollismo o neo-keynesianismo.

En el segundo trabajo, Beatriz Cuenya reflexiona sobre el contexto de las políticas habitacionales desarrolladas en los últimos años en América Latina (específicamente Brasil, Argentina y Chile), cuyo principal objetivo es la inclusión, aunque no siempre se logra, ya que enfrentan a sectores que se oponen a la función social de la propiedad y a la feroz competencia por el suelo. La autora manifiesta la preocupación por el fenómeno de segregación socio espacial en el espacio urbano, cada vez más extenso y menos densificado. Cuenya también describe algunos de los problemas que surgen como consecuencia de la aplicación de las políticas, entre ellos la gran extensión de las ciudades, más gastos en tiempo, homogeneización de las viviendas, problemas sociales relacionados con el rechazo a los nuevos habitantes, etc. y plantea la necesidad de abordar articuladamente el tema de la vivienda social con el funcionamiento de la ciudad. 
En el tercer trabajo, Mercedes Lentini reconoce, en primer lugar, la necesidad de mostrar que el hábitat residencial es de "naturaleza compleja y multidimensional", por lo que el tema de la vivienda debe abordarse teniendo en cuenta lo económico (bien material) lo territorial (espacio) y lo ambiental (problemas) ya que la demanda de vivienda no se resuelve solamente con la entrega del techo, sino con un conjunto de aspectos que incluyen la seguridad, accesibilidad, integración, etc.

Seguidamente, la autora incluye la política habitacional en el campo de las políticas públicas y sociales, como punto de partida para el análisis político, destacando el rol del Estado como productor de vivienda, como regulador (mediante normas), agente fiscal y de mercado. Finalmente, hace mención al tema del gasto público que demanda el tema de la vivienda en América Latina como indicador de prioridades del accionar de los gobiernos; concluyendo que la inversión en vivienda nunca ha sido prioritaria por sobre otros sectores sociales.

En el cuarto trabajo, Miguel A. Barreto y su grupo de trabajo exponen un conjunto de conceptos que forman parte del marco teórico y metodológico utilizado específicamente en un estudio, tales como política habitacional, vivienda social, pobreza, hábitat integral y su relación con el trabajo. Exponen además la metodología aplicada para localizar asentamientos y nuevas viviendas en el espacio, lo cual permite también observar de manera general la característica urbana ambiental y habitacional de los distintos barrios. Luego, expresan la necesidad de reconocer la multidimensionalidad (habitacional, urbano-ambiental, económica-social-cultural, legal, política) del problema de la vivienda, en la que predomine la articulación intersectorial e interjurisdiccional de las políticas habitacionales, a fin de desalentar la extensión innecesaria y discontinua de los espacios urbanos y promoviendo tanto la vivienda como el hábitat adecuado.

En el quinto y último trabajo Gonzalo R. Merkel y Jorge M. Motta exponen, en primer lugar, el déficit habitacional con una metodología para medirlo tanto cuali como cuantitativamente, complementado con una metodología para el análisis de la situación habitacional (IAIVA-Indicadores y Aplicación de Información sobre Vivienda en Argentina) desarrollada conjuntamente por la Universidad Nacional de Quilmes y la Subsecretaría de Desarrollo Urbano y Vivienda. Escriben también sobre la falta de monitoreo y evaluación de las políticas de viviendas implementadas por parte del Estado ya sea por que éstas no se formulan lo suficientemente claras o los objetivos perseguidos no son los obtenidos. Según los autores la evaluación, en general -de políticas y programas- se hace desde la academia. Un aporte importante del documento lo comprenden los ejemplos con dimensiones e indicadores de monitoreo de programas, índices e impactos. 
La segunda parte del libro comprende, en primera instancia, dos trabajos en los que se trata específicamente la política habitacional argentina a comienzos del Siglo XXI y luego tres investigaciones que muestran los resultados de la implementación de algunos programas de la Política Federal de Vivienda.

En el primero de ellos, a cargo de María B. Rodulfo y Teresa Boselli, se remarca claramente la importancia de la política actual como respuesta al déficit y a la demanda social de vivienda nacional. Para llegar a la situación actual, muestran una evolución del sistema desde la creación del Fondo Nacional de la Vivienda (FONAVI), caracterizando claramente las políticas centralizadas, descentralizadas, además de la recentralización de los últimos años. Las autoras abordan la inversión en vivienda -por provincia- por parte del Estado mediante el análisis de la evolución de las transferencias tanto del FONAVI como de los programas correspondientes a la Política Federal de Vivienda.

En el segundo, a cargo de Delia Palero y Mercedes Lentini, se caracterizan los problemas de la política habitacional en la década del noventa caracterizada por la descentralización, y los cambios a partir del nuevo siglo. Las autoras relacionan el pasado del sistema y la actualidad a fin de establecer lineamientos que sirvan de guías y recomendaciones, a la vez que incluyen el tema de los asentamientos humanos sostenibles, acceso al suelo, atención a la pobreza. Finalmente, analizan el impacto que los programas de vivienda han tenido en la provincia de Mendoza.

El resto de los trabajos de la obra muestran el resultado de estudios realizados en el área metropolitana de Buenos Aires, como es el de Beatriz Cuenya, que centra su estudio en el tipo de ciudad que se construye mediante la política habitacional implementada desde el año 2003. El trabajo de Miguel Barreto y su equipo muestra los resultados de la puesta en marcha del programa Federal Solidaridad Habitacional en un barrio de la provincia de Chaco; y el trabajo de Ana Falu y Cecilia Marengo busca dar cuenta de los resultados del Plan Federal de Vivienda en Córdoba.

Concluyendo, la obra constituye una excelente y completa síntesis de las investigaciones realizadas por expertos en el tema de la vivienda y de las políticas habitacionales implementadas en Argentina, tanto desde el punto de vista teórico, metodológico como empírico. La obra contiene experiencias y resultados que pueden ser fácilmente utilizados en otros espacios de estudios, cumpliendo con uno de los objetivos planteados por la Red de Estudios de la Política Habitacional Argentina que es ser observatorio. Sin duda el libro es de significativo valor académico-científico y de gran aporte al conocimiento. 